\title{
Death as a Consequence of a Hip Fracture After a Fall; to Be Further Investigated?
}

\author{
Annelieke MK. Harmsen, ${ }^{1,}$ Udo JL. Reijnders, ${ }^{2}$ and Georgios F. Giannakopoulos ${ }^{1}$ \\ ${ }^{1}$ Department of Trauma Surgery, VU University Medical Centre, Amsterdam, The Netherlands \\ ${ }^{2}$ Department of Forensic Medicine, Public Health Service, Amsterdam, The Netherlands \\ "Corresponding author: Annelieke MK. Harmsen, Department of Trauma Surgery, VU University Medical Centre, Amsterdam, The Netherlands. Tel: +31-204443529, Fax: \\ +31-204444512, E-mail: a.harmsen@vumc.nl
}

Received 2015 October 09; Accepted 2015 November 29.

\begin{abstract}
Although it is not often thought of, elderly abuse is a frequently occurring phenomenon. Especially when an older patient dies, maltreatment is low on the list of possible causes of death. There are, however, signs that may point in the direction of abuse. These can either be on the patient's body, in the surroundings, or within the story as to how the patient died. Attention should be paid to these often subtle signs, and autopsies need to be performed more frequently to establish the exact cause of death.
\end{abstract}

Keywords: Trauma Patients, Missed Injuries, Abuse, Intentional Asphyxia

\section{Introduction}

Approximately $5 \%$ of the elderly population $(\geq 65$ years old) in the Netherlands is involved with various types of abuse. This results in 160000 cases annually. Elderly people with dementia (270000) are involved even more frequently (30\%), of which $1 \%$ relates to physical abuse (1). In the United States, 1 - 2 million elderly are harmed annually (2). Because of the gradual rise of elderly people in the population, this number will increase as a consequence. The exact number of elderly people who die as a consequence of physical abuse is unclear. One of the reasons for this is that not all abuse is overt and sometimes an autopsy is necessary to establish the exact cause of death. Unfortunately, many autopsies are performed by the attending physician, are insufficient, and are not extensive enough to identify abuse-related trauma. Almost $75 \%$ of all physicians admit to not being able to identify injuries caused by abuse (3, 4). There is no special Dutch legislation, nor obligation of health care staff, for the prevention of elderly abuse. An autopsy is deemed necessary, however, when there is suspicion of an unnatural death as determined by the forensic physician who is brought in at the request of either the attending physician or the police. The forensic physician decides if there is reason to suspect an unnatural cause of death. In the case of an unnatural cause of death, the forensic physician determines if an autopsy is necessary. This is reported to the police and the district attorney, who decide if a legal autopsy is required. The above mentioned procedure varies among countries (5). Each year in the
Netherlands, almost 700 legal autopsies are performed out of 140000 deaths (0.5\%). In Germany, it occurs in $1.5 \%$ of all deaths and in England, the annual autopsy rate reaches almost $130000(6,7)$. When there is reason to suspect an unnatural death, it is usually the result of an accident. What seems like an innocent accident may acquire an interesting approach, especially amongst the elderly, as described in the following two cases of patients in their eighties.

\section{Case Presentation}

\subsection{Case 1}

A woman was brought in by ambulance to an emergency department. She was found at the bottom of the stairs. Investigation by the attending surgeon concluded that she had suffered a hip fracture, and it was decided that she should be treated with internal fixation. Her postoperative recovery was slow and she developed pneumonia. Despite optimal care, she died after 19 days, as a result of sepsis.

Because the death was originally caused by a fall, thus an unnatural death, the forensic physician was consulted. The clinical charts were reviewed and provided no additional information than mentioned above. The body was investigated and a large operational scar was seen on the hip. After consultation with the district attorney, the body was released. The following day, the forensic physician contacted the deceased's own general physician and informed 
him that an autopsy had been performed. During the conversation, the physician revealed that he had seen this patient regularly in the last two years and observed wounds spread over her body which were believed to be caused by her grandson who was living with her. The grandson never spoke to anyone in fear of reprisal. The forensic physician contacted the district attorney because there was now cause for suspicion. The corpse was then repossessed and an investigation started. The grandson was brought in for questioning, and admitted to having thrown his grandmother down the stairs.

\subsection{Case 2}

A man was admitted to a surgical department with a right pertrochanteric fracture of the femur, sustained after a fall at home. Because of his frail condition and his cardiopulmonary status, it was decided not to operate but to proceed with conservative management. Three days later, the surgeon discussed the man's case with his son and explained that an operation would not be an option given the considerable risks involved. Five minutes after the surgeon left the room, the son informed the staff that his father had collapsed. He seemed to have died, which was not unexpected. The forensic physician was called in because the death involved a fall, which is considered to be an unnatural death. The autopsy revealed petechial hemorrhages on the inner eyelids and mucous membrane of the lower lip; these findings may indicate intentional asphyxia. After questioning, the son admitted to having taken matters into his own hands, smothering his father with a pillow until he suffocated.

\section{Discussion}

An "unfortunate fall down the stairs" is often the explanation given for injuries sustained by an elderly person, though these events are not always accidental but often, rather, intentional (8). The recognition of inflicted and intentional wounds by physicians and nurses is insufficient $(3,4)$. Nevertheless, staff working in emergency departments are important health care providers for victims of domestic violence and could therefore play an important role in early detection and assessment of injuries (2). It is therefore essential that the physical examination after trauma is recorded in the clinical chart. After a fall (mostly forwards), injuries are expected to be localized at the front of the head, chin, hands, palms, elbows, lower arms, knees, and lower legs. In the case of an unintentional fall, abrasions are more often seen than in the case of an inflicted injury. Injuries on other parts of the body are often suspected to be caused by violence. The most common sites of injury are the eye, the side of the face, the throat and neck, the upper and lower arms, and the upper and lower legs. These injuries are mostly caused by punching the eye, striking the side of the face with a flat hand, and by attempts of strangulation. Injuries as a consequence of self-defense can be seen as well on the upper and lower arm (from defending with punching) and on the upper and lower legs (from defending with kicking). Other injuries may be found around the mouth (beating and punching), on the outside of the hand (injury of defense), the back and the shoulder(by throwing the victim against an object or on the ground), the scalp (by beating with an object or by tearing the hair), and the thorax (by throwing over or punching) (9). Multiple bruises in various stages of healing on obscure parts of the body are usually an indication of inflicted injury. The observation of repeated linear wounds (tramline bruising) often indicate the use of an object (e.g. stick). Fingertip bruising often observed indicates pinching or violent grabbing. Most bruises disappear after two or three weeks and are then insufficient for assessment. In the first case, reporting the wounds found on the body upon admission to the hospital would have facilitated determining the cause of death. A high percentage (approximately 30\%) of elderly patients with hip fractures die as a result of complications of illnesses and treatment (10). The second case indicates that, although death was anticipated, the autopsy should always include a full body examination of the corpse. Misconduct can more easily be detected after an originally unsuspicious accident and, consequently, more research will follow.

In conclusion, the possibility of violence should be considered as the possible cause of death for every deceased, elderly trauma patient. Training in this field is very essential for all professionals involved.

\section{Footnote}

Conflict of Interest: All authors declare that they have no conflict of interest.

\section{References}

1. Comijs HC. Elder mistreatment: Prevalence, risk indicators and consequences [thesis]. Amesterdam: Vrije Univ.; 1999.

2. Guth AA, Pachter L. Domestic violence and the trauma surgeon. Am J Surg. 2000;179(2):134-40. [PubMed: 10970242].

3. Reijnders UJ, Giannakopoulos GF, de Bruin KH. Assessment of abuse-related injuries: a comparative study of forensic physicians, emergency room physicians, emergency room nurses and medical students. J Forensic Leg Med. 2008;15(1):15-9. doi: 10.1016/j.jcfm.2006.06.029. [PubMed: 17011810].

4. Reijnders UJ, van Baasbank MC, van der Wal G. Diagnosis and interpretation of injuries: a study of Dutch general practitioners. J Clin Foren sic Med. 2005;12(6):291-5. doi: 10.1016/j.jcfm.2005.03.003. [PubMed: 16301163]. 
5. Das C. Death certificates and doctors: rules and reality [Thesis]. Amsterdam: Vrije Universiteit; 2004.

6. Spann W, Maidl K. Die Frequenz gerichtlicher Leichenöffnungen in der Bundesrepublik Deutschland. MedR. 1985;2:59-62.

7. Dean P. McLay. Clinical Forensic Medicine. London: Greenwich: Medical Media;1996. Death and its Investigations.

8. Reijnders UJL. Baasbank MC van, Wal G van der. Van de trap gevallen: Drie van de vier artsen herkennen mishandeling niet. Medisch Contact. 2004;59(43):1678-9.
9. Reijnders UJ, van der Leden ME, de Bruin KH. [Injuries due to domestic violence against women: sites on the body, types of injury and the methods of infliction]. Ned Tijdschr Geneeskd. 2006;150(8):429-35. [PubMed: 16538843].

10. Brauer $\mathrm{CA}$, Coca-Perraillon $\mathrm{M}$, Cutler $\mathrm{DM}$, Rosen $\mathrm{AB}$. Incidence and mortality of hip fractures in the United States. JAMA. 2009;302(14):1573-9. doi: 10.1001/jama.2009.1462. [PubMed: 19826027]. 